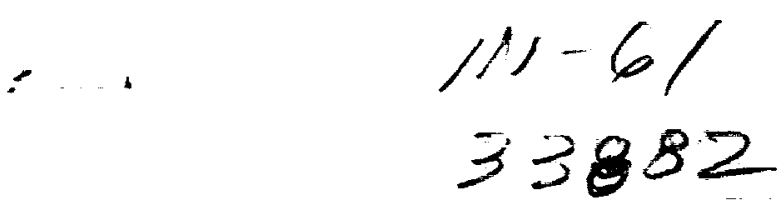

NASA Technical Memorandum 106799

AIAA-95-0070

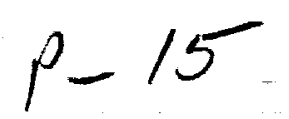

\title{
A Workstation Based Simulator for Teaching Compressible Aerodynamics
}

Thomas J. Benson

Lewis Research Center

Cleveland, Ohio

(NASA-TM-106799) A WORKSTATION BASED SIMULATOR FOR TEACHING COMPRESSIRLE AEROOYNAMICS (NASA. Lewis Research (enter) $15 \mathrm{p}$
N95-16906

Unclas

G3/61 0033882

Prepared for the 33rd Aerospace Sciences Meeting sponsored by the American Institute of Aeronautics and Astronautics Reno, Nevada, January 9-12, 1995

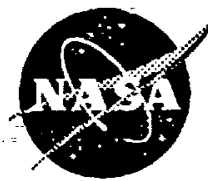

National Aeronautics and Space Administration 


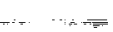
$+2$ $\ldots$ $F=-\cdots$

$=--1-\cdots$

$-$ $\because \cdots,--\cdots=$
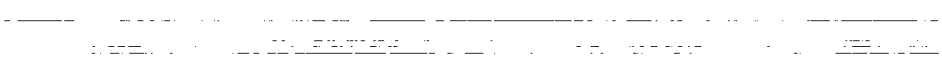

\section{$f=-1$}

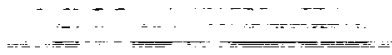

- - - -

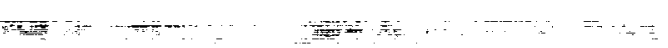

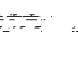

$-\ldots$

$=$

$$
\therefore-\cdots
$$




\title{
A Workstation Based Simulator for Teaching Compressible Aerodynamics
}

\author{
Thomas J. Benson* \\ NASA Lewis Research Center \\ Cleveland, Ohio 44135
}

November 18, 1994

\begin{abstract}
A workstation-based interactive flow simulator has been developed to aid in the teaching of undergraduate compressible aerodynamics. By solving the equations found in NACA 1135, the simulator models three basic fluids problems encountered in supersonic flow: flow past a compression corner, flow past two wedges in series, and flow past two opposed wedges. The student can vary the geometry or flow conditions through a graphical user interface and the new conditions are calculated immediately. Various graphical formats present the results of the flow calculations to the student. The simulator includes interactive questions and answers to aid in both the use of the taol and to develop an understanding of some of the complexities of compressible aerodynamics. A series of help screens make the simulator easy to learn and use.

\section{INTRODUCTION}

The last decade has witnessed a revolution in the availability, computing power, and memory capacity of personal computers and workstations. Current desk top workstations provide computing power available only on large mainframes in the past. Coupling this hardware growth with new operating systems, windowing capability, and the development of graphical user interfaces (GUI) creates an entirely new computing environment. Interestingly,

\footnotetext{
*Senior Research Engineer, Member AIAA

${ }^{\circ}$ Copyright c 1994 by the American Institute of Aeronautics and Astronautics, Inc. No copyright is asserted in the United States under Title 17, U.S. Code. The U.S. Government has a royalty-free license to exercise all rights under the copyright claimed herein for Governmental purposes. All other rights are reserved by the copyright owner.
}

it is an environment in which young students feel quite at home having grown up with video games and personal computers at school or in the home. The software tool described in this paper attempts to use this new technology to improve the basic understanding of compressible aerodynamics by undergraduates.

The use of personal computers and workstations in undergraduate engineering education is a relatively recent development. Earlier efforts (Refs 14) have centered around the use of software developed for personal computers, but lacking the graphical interface available on workstations. With these packages, students type input conditions at the keyboard and are presented with principally numerical output. More recent efforts (Refs 5-7) have included a graphical user interface that guides the user through the package and improves the interaction with the software. With these packages, students use a mouse to select options or to vary conditions and receive principally graphical output. The simulator described in this paper is an extension of a preliminary educational tool developed at the NASA Lewis Research Center, Ref. 6, which in turn was developed from a supersonic inlet design and educational tool, Ref. 7. The Lewis simulators solve the equations from NACA-1135, Ref 8 , to quickly determine the flow conditions across shock waves generated by compression surfaces. It became evident during development of the inlet simulator that it could be used either for preliminary design or for graduate level education since it modeled most of the important physical processes present in high speed inlets. However the many processes involved in a typical inlet, including the modeling of the subsonic diffuser and computation of flow spillage and 
its associated drag, rendered the tool too complex for undergraduate education. By limiting the problem to a single physical process of flow compression (or expansion) the undergraduate could more easily study the details of this problem. Since much of the coding was already available, the development of the preliminary educational tool was easily completed. The current simulator is an extension of this preliminary model and incorporates the solution of shock reflections and intersections which were not present in the first model. This added solution capability allows the student to explore problems involving multiple surfaces, opposing wedges or wedges in series.

A guiding principal in the development of this educational tool is to do more than just present answers to a problem; it is to involve the student in the learning process by making the student work with the package to achieve a result. Some new features were added to this tool to directly promote student interaction. The student is presented with a physics problem in one view window of the computer terminal. In another window is a control panel which the student uses to vary the conditions of the physics problem and in a third window raw output data from the problem is presented to the student. The student can then select which data to analyze in a fourth window, where the results are presented as performance graphs. A series of "Help" screens are available to explain how each part works and serves as an on-line user's manual.

The desk top wind tunnel concept could be used in many areas of undergraduate education. The current tool can be rather easily modified to consider alternate physics problems, such as a supersonic nozzle, a sting-mounted wedge at angle of attack, or a diamond airfoil. The basics of the code could be retained and other classes of fluids problems coded, including potential flow, conformal mapping, basic turbojet analysis, and airfoil theory. Many basic thermodynamics, magnetics, electrostatics and optics problems also lend themselves to presentation in this way.

\section{ANALYSIS}

The inviscid, supersonic flow past a corner results in one of three possible physical processes: (1) a normal shock detached from the corner at large positive wedge angles; (2) an oblique shock attached to the corner at low to moderate positive angles; and (3) a Prandtl-Meyer centered expansion at the corner for negative wedge angles. The boundary between attached and detached shock waves can be determined as a function of the upstream Mach number. The equations used in the simulator are taken from Ref. 8 and the reader can find details of the method of solution for a single wedge problem in Ref. 6 .

For multiple wedges two additional physical processes are present; shock (or expansion) reflection from solid surfaces, and shock (or expansion) intersection away from solid surfaces. For simplicity, only shock waves will be considered in this analysis. In the shock reflection problem, as shown in Fig. 1, the incoming shock turns the flow behind it by a known angle. When the shock strikes the wall it is reflected with the angle of reflection and the change in conditions across the reflected shock determined by the angle of incidence and the strength of the incoming shock. The flow downstream of the reflected shock is parallel to the wall. The equations used to compute the conditions behind the reflected shock are those given in Refs 6 and 8 with the "wedge" angle equal to the turning angle behind the incoming shock. The computational problem is simply one of locating the reflection point and properly orienting the problem to use the previously developed flow equations. There are conditions for which the required amount of turning exceeds the maximum allowable for an attached oblique shock. Under these conditions, a shock normal to the wall is formed and the normal shock relations are used to bring the flow to subsonic conditions which will support the turning.

The shock intersection problem can occur in two forms: between incoming shocks of the same family which are each turning the flow in the same direction as shown in Fig. 2a, or between incoming shocks of opposite families which are turning the flow in opposite directions as shown in Fig. 2b. Details of these interactions are given in Ref. 9. For shocks of opposite families, the shocks appear to pass through each other but are bent at the intersection point. For shocks of the same family, the shocks appear to coalesce into a single continuing shock from the intersection point with an extremely weak shock (or expansion) reflected from the intersection point. In both problems all flow downstream of the intersection is at the same static pressure and in the same flow direction. Because different parts of the flow 
may have passed through different strength shock waves, a slipstream can be formed at the intersection point as indicated in Fig. 2. Flow on either side of the slipstream is at different Mach number, temperature, entropy, or total pressure, but at the same static pressure and flow direction.

The solution of the flowfield proceeds as follows. The wedge deflection angles and free stream conditions are set by the user. Shock solutions for the wedges are generated using the equations given in Ref. 6. The intersection of shock waves with other shock waves and with the walls is determined geometrically. For a shock reflection from the wall, a new shock is begun at the reflection point and the downstream conditions are determined by the equations of Ref. 6 using a deflection angle which brings the flow parallel to the wall. This new shock is then checked for intersection with other shocks or reflection from the walls as before and the process is repeated. For shock intersections, two new shocks are begun at the intersection point. Conditions downstream of the shock intersection are found by iterating the solutions on either side of the slipstream until both static pressure and flow direction are equal. The new shocks are then checked for intersection with other shocks or reflection from the walls as before and the process is repeated. Whenever the deflection conditions would exceed the maximum allowable deflection, a normal shock is drawn across the flowfield, subsonic conditions downstream of the normal shock are determined, and the solution is terminated. In reality, some complex mixed subsonic/supersonic conditions can arise in these types of problems. In this simulator we do not attempt to compute these types of conditions but merely indicate the presence of subsonic flows by placing a normal shock across the flow domain.

\section{DESCRIPTION OF SIMULATOR}

Some examples of the results obtained using the simulator are given by screen dumps in Figs 3-8. Fig. 3 shows the basic layout of the simulator which is divided into four main sections: the main view window is in the upper left, the plotter view window is in the upper right, the output box is in the lower right, and the input box is in the lower left.

The main view window shows a schematic drawing of the geometry, the shocks (or expansions), and labels for the hinges and the wedges. On the workstation, these features are color-coded, but are presented here in black and white. The wedges appear as the nearly horizontal lines with the small semi-circles denoting the hinge locations. The flow is from left to right as indicated by the arrow and the various flow zones downstream of the shocks are tagged with zone numbers. Sliders are located to the left and below the main view window to allow repositioning of the flow problem within the window.

The plotter view window is located to the right of the main view window and displays the plots generated by the student. The student can select which sets of variables to plot using the input box as described below. The size and orientation of the plot can be modified by the sliders located around the plotter view window. Details of the generation of plots is discussed below. Above the plotter window are four buttons which invoke various utilities for the simulator. Details on the operation of these features can be found in Ref. 6 .

The computed output flow conditions are displayed in the output box below the plotter view window. The zone choice button at the top is used to choose which flow zone to display with the zone numbers corresponding to the tags in the main view window. The data is presented in two ways: numerically in the row of boxes at the left, and as bar charts to the right. Each bar is a different color corresponding to a different flow variable. The top bar shows the shock angle in degrees, the bar below that shows the total pressure ratio from zero at the left to one on the right. The bottom four bars are grouped somewhat because the scale on these four bars are from zero to ten. Numbers at the bottom of the panel aid the student in evaluating the bars, though the exact value can also be obtained from the numerical boxes. As the flow conditions are changed in the input box, the recalculated numbers are displayed and the bar charts move much like a thermometer. This type of visual output allows the student to immediately sense in what direction the flow variables change and by how much for a given input. Variables displayed in the bar charts are nondimensionalized by free stream conditions while the row of boxes at the bottom show the ratio of the appropriate variables across the shock wave.

The input box is located to the left of the output 
box. It includes three buttons to select the problem for study and four sub-panels to vary conditions in the problem. The selected problem is indicated by the darkened "light" on the button. The upper two sub-panels control the geometry and free stream flow conditions while the lower two control the generation of plots. In the upper control panels, the student can type in values of the geometric or flow parameters or use sliders to pick these variables. The choice is indicated by pushing the "Sliders/Enter" buttons between the slider and the input box as shown in Figs. 3 and 5. The student can vary the free stream Mach number, the values of the wedge angles and the spacing between the wedges, depending on the problem selected. More details about the operation of the plotter sub-panels will be given in the next section.

\section{RESULTS}

Ref. 6 contains several examples of the use of the simulator to study single wedge problems; this paper presents only solutions to multiple wedge problems. The simulator can be operated in two modes; interactive mode and plotting mode. In the interactive mode, the student can vary the Mach number, wedge angles and spacing using the input box and monitor the changes of the dependent flow variables using the output box. By observing the output numbers and bar charts, the student can get a sense of the variation of the dependent variables as independent conditions are changed. To study the variation of a single flow variable through the interaction, the simulator should be run in plotting mode. For the corner problem, the student can plot any of the dependent flow variables versus changes in either the Mach number or the wedge angle. For the multiple wedge problems, the student can position a "probe" in the main view window and record the value of a chosen flow variable versus location. As the student develops the plots, they are automatically scaled and displayed in the plotter window.

Figures 3-6 can be used again to demonstrate how a student might use the interactive mode of the simulator. As the input is varied the simulator recalculates the flow conditions and instantly changes the geometry and shock orientation to reflect the new conditions. In Fig. 3, Mach 2.5 flow past two 10.0 degree wedges has been calculated resulting in the intersection of two shocks of the same family.
The shocks tagged " 1 " and " 2 " appear to coalesce into the shock tagged " 3 ". For this set of conditions a very weak secondary expansion, tagged " 4 " is necessary to match the static pressure and flow deflection conditions downstream of the intersection and a slipstream is generated between zones 3 and 4 as indicated by the dashed line. The results presented in the output box give the conditions in zone 3 downstream of shock " 3 ". These results have been checked against the NACA-1135 curves to insure proper coding. Figure 4 shows the same physics problem but with zone 4 conditions now given in the output box. Comparing Figs. 3 and 4 , one can verify that the flow turning and static pressure are the same, while the remaining flow variables differ. In Fig. 5, the student has decided to study the shock reflection problem at Mach 2.3 with a 10.0 degree wedge shock generator. The shock reflects from an opposed wedge set at 0.0 degrees to eliminate additional shocks and their intersections. The conditions shown in the output box are those in zone 2, downstream of the reflected shock. The ratio boxes at the bottom of the output box refer to conditions across shock " 2 ", i.e. the ratio of zone 2 to zone 1 , while the conditions on the bar graphs show the ratio of zone 2 to zone 0 , free stream. Comparing these results for static pressure indicate that zone 2 is slightly more than 3.0 times free stream pressure, while only 1.7 times the pressure behind the incident shock. In Fig.6, the student has increased the upper wedge angle from 0.0 degrees to 5.0 degrees. The generated shocks are of unequal strength, opposite family, and intersect with each other then reflect from the opposing wedge producing a diamond shock pattern. At the shock intersections, slipstreams are formed as indicated by the dashed lines in the main view window. The output box shows conditions in zone 3 , the lower part of the first diamond. The flow in zone 3 , as well as the slipstream, are inclined at $\mathbf{5 . 0}$ degrees to the horizontal while the flow in zone 1 is 10.0 degrees and zone 2 is -5.0 degrees.

In plotting mode, the simulator behaves like a desk top wind tunnel. The plotter is invoked by pushing the "ON" button in the left sub-panel of the input box, as shown in Fig. 7. In the main view window a set of axes, labeled " $X$ " and " $Y$ " appear as does a set of cross-hairs which define the location of a probe. The user pushes the "New Plot" button to enable the choice buttons in the right sub-panel 
marked "Probe". Here, the student chooses a dependent variable from the upper group of six variables versus a direction chosen from the lower two buttons. As the choices are made, the axes in the plotter view window are automatically labeled and scaled. In Fig. 7, the user has chosen to plot static pressure ratio versus $\mathrm{X}$ direction as indicated by the lights on the buttons. The student moves the "Y" slider in the "Probe" sub-panel and the cross-hairs move in the main view window until the desired location is found. The student then pushes the "Begin Trace" button which freezes the $Y$ location of the cross hairs. The user then varies the " $\mathrm{X}$ " slider to any desired value and presses the "Take Data" button. At this point a "*" appears on the graph corresponding to the chosen value of $\mathrm{X}$ direction and calculated value of dependent variable (pressure ratio). The student then uses the "X" slider to select a new $X$ location and again "Take Data". A new point appears on the plot and the procedure is repeated to a maximum of twenty five data points. The data can be taken in any order, so the student can fill in interesting portions of the curve. In Fig. 7, eleven data points have been taken. When the student has completed a trace, the "End Trace" button is pushed which frees the "Y" slider, draws a solid color-coded line through the data, and affixes a colored label with the value of the $Y$ location. The student can then choose a new value of $Y$ and begin a new trace as before. Fig. 8 shows the screen dump after the student has begun a new trace. In this example, eight data points have been taken along the new trace, and the old trace has been labeled in the upper right corner of the plotter window. The probe is now located in zone 4 . The student can put up to five traces on the plotter. To begin a new plot, the student pushes the "New Plot" button, the old plots are erased, the count boxes for traces and data are reset to zero, and the "Probe" buttons can be used to pick new independent and dependent variables.

Since no educational tool would be complete without an examination, a question and answer box has been added at the lower right corner as shown in Fig. 8. The questions and answers are stored in a data file which the simulator accesses. Teachers can edit this data file and add, modify, or delete questions and answers as required. To operate this feature, the student pushes the "Question" button for a question, then uses the simulator to obtain an answer, then presses the "Answer" button to check the answer. The questions can appear in the window either sequentially or randomly as chosen by the student with the appropriate buttons. The current set of questions and answers initially presents easy questions to promote an interaction of the student with the simulator. Gradually, more difficult questions are introduced. If the student chooses the random order of presentation, difficult and easy questions are intermingled. As currently configured, the simulator runs through the same questions every time the simulator is invoked. This portion of the tool can be modified to present questions from different data files or even questions with a timer but without the provided answers - a true examination tool.

\section{SUMMARY}

A workstation-based, highly interactive educational tool for compressible aerodynamics has been developed. The tool is an extension of an earlier model and can now solve three flow problems: flow past a corner, flow past two wedges in series, and flow past two opposing wedges. The underlying assumptions and analysis techniques which form the basis for this tool have been presented in this paper, as well as several examples of results from the simulator. The tool employs two basic ideas to help undergraduates better understand fluid mechanics. First, the student is required to interact with the tool to produce results. The student is in control of the parameters defining the problem and must perform several steps to produce the plotted output. The question and answer box also requires the student to act and not merely observe. Second, the output results are presented to the student in a variety of forms. For a given flow problem the student can see a schematic of the geometry, the shock location and interactions, tabulated numbers of the dependent flow variables, moving bar charts of the flow variables, and plotted data. Further extensions of this technology into other flow regimes and other physics problems are planned.

\section{ACKNOWLEDGEMENTS}

The current simulator uses the FORMS library of GUI developed by Mark H. Overmars, Department of Computer Science, Utrecht University, 
The Netherlands for Silicon Graphics workstations. Some modifications to this library have been made to allow the package to also be used on IBM Risc 6000 machines. All of this software is public domain and may be copied and used for non-commercial products, but not resold. Copies of the source are available from the author at the NASA Lewis Research Center.

\section{REFERENCES}

1. Mattingly, J.D., Heiser, W.H. and Daley, D.H., Aircraft Engine Design, AIAA Education Series, Washington, D.C., 1987.

2. Koening, K. and Hodge, B.K., "A Suite of Personal Computer Programs to Support Propulsion Education", AIAA 93-2053, June, 1993.

3. Fox, R.W., and McDonald, A.T., Introduction to Fluid Mechanics, John Wiley, New York, 4th ed., 1992.

4. Hodge, B.K. and Koening, K., "SOLROC, A Solid Rocket Motor Internal Ballistics Software Element", AIAA 94-3115, June, 1994.

5. Torella, G. and Lombardo, G., "Computer Codes for the Training on Auxiliary Power Units (A.P.U.)", AIAA 94-3113, June, 1994.

6. Benson, T.J., "An Interactive Educational Tool for Compressible Aerodynamics", AIAA 943117, June, 1994.

7. Benson, T.J., "An Interactive, Design and Educational Tool for Supersonic External-Compression Inlets", AIAA 94-2707, June, 1994.

8. Ames Research Staff, "Equations, Tables and Charts for Compressible Flow", NACA Report $1135,1953$.

9. Liepman, H.W. and Roshko, A., Elements of Gasdynamics, Wiley and Sons, London, 1957, pp. 100-103. 


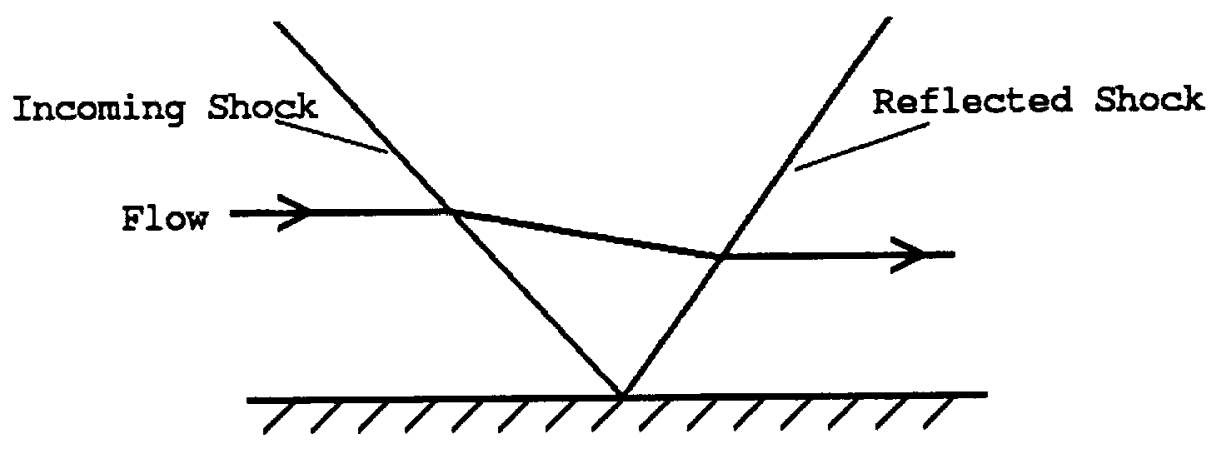

Fig. 1 Reflecting shock.

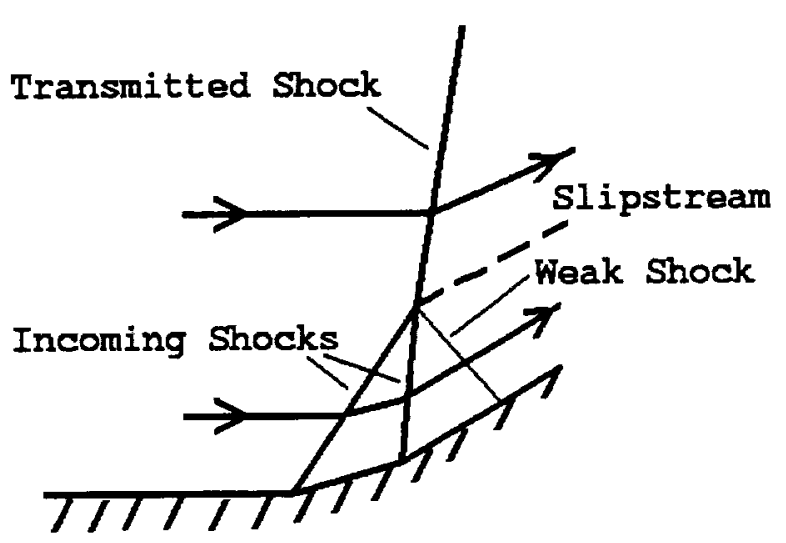

a. Same family.

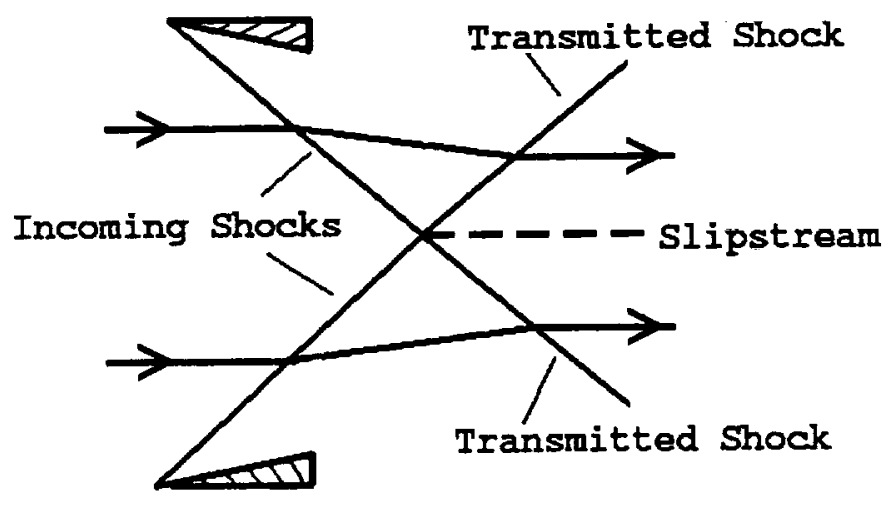

b. Opposite family.

Fig. 2 Intersecting shock. 


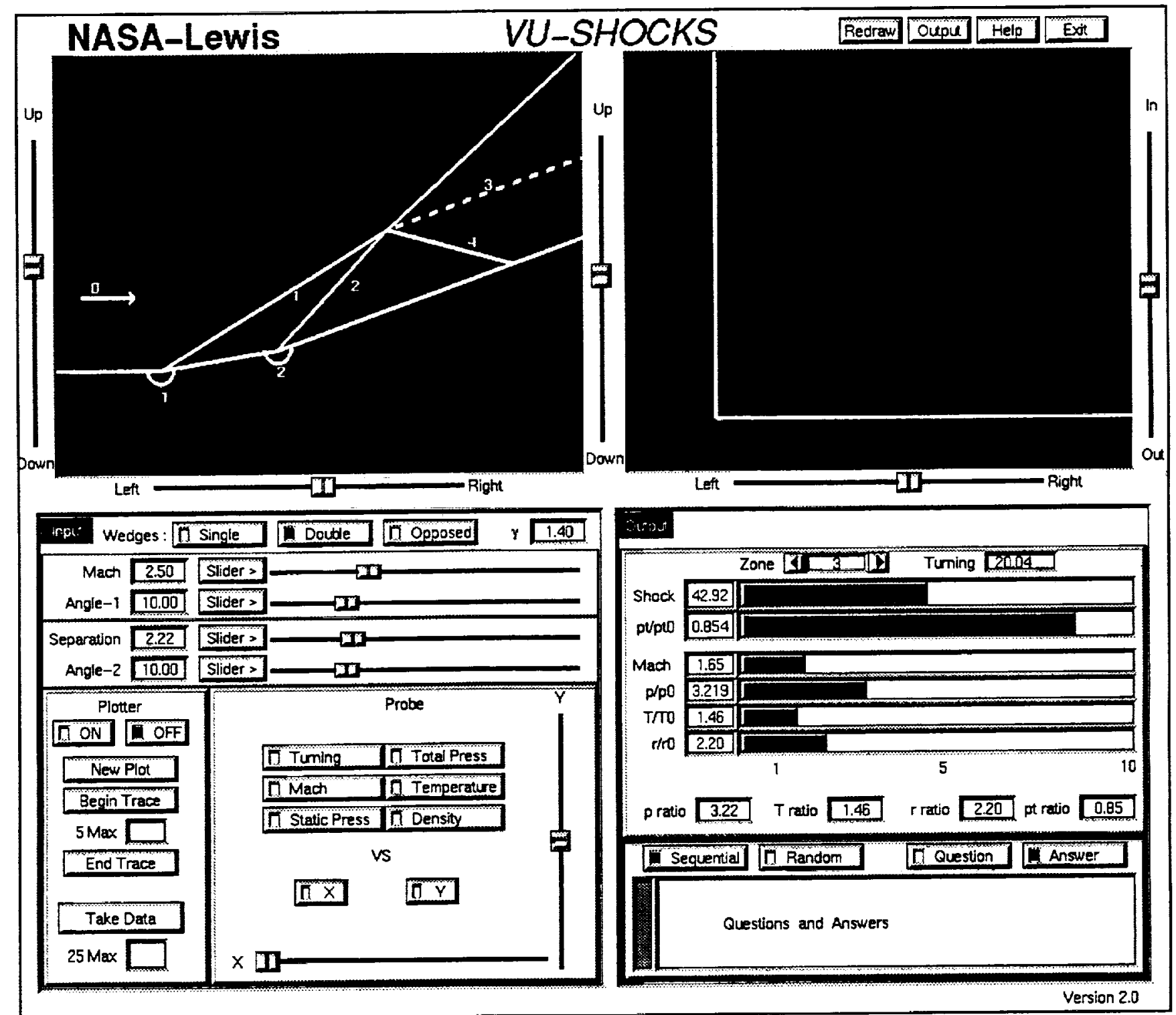

Fig. 3 Simulator screen durap. 


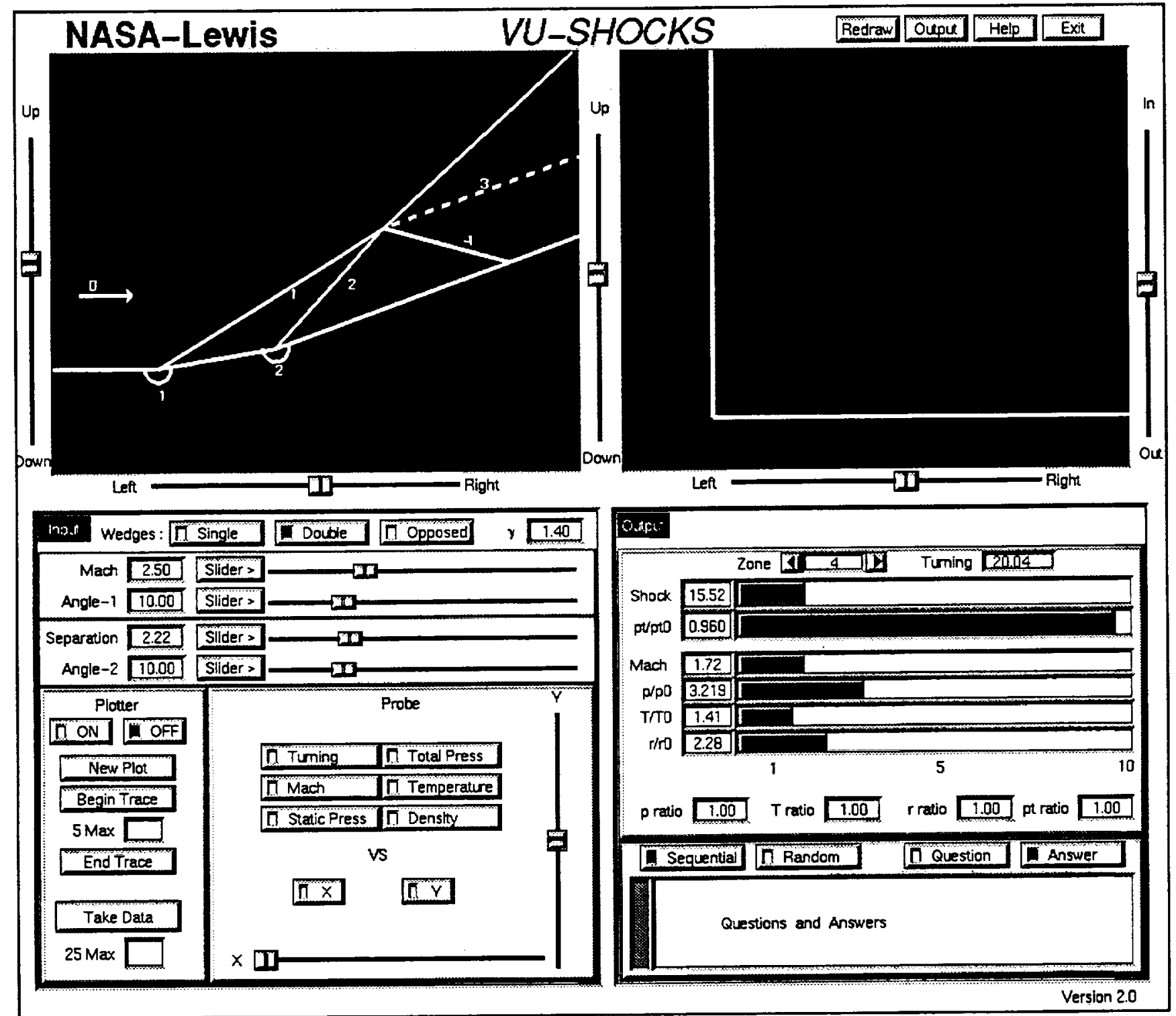

Fig. 4 Zone 4 output. 


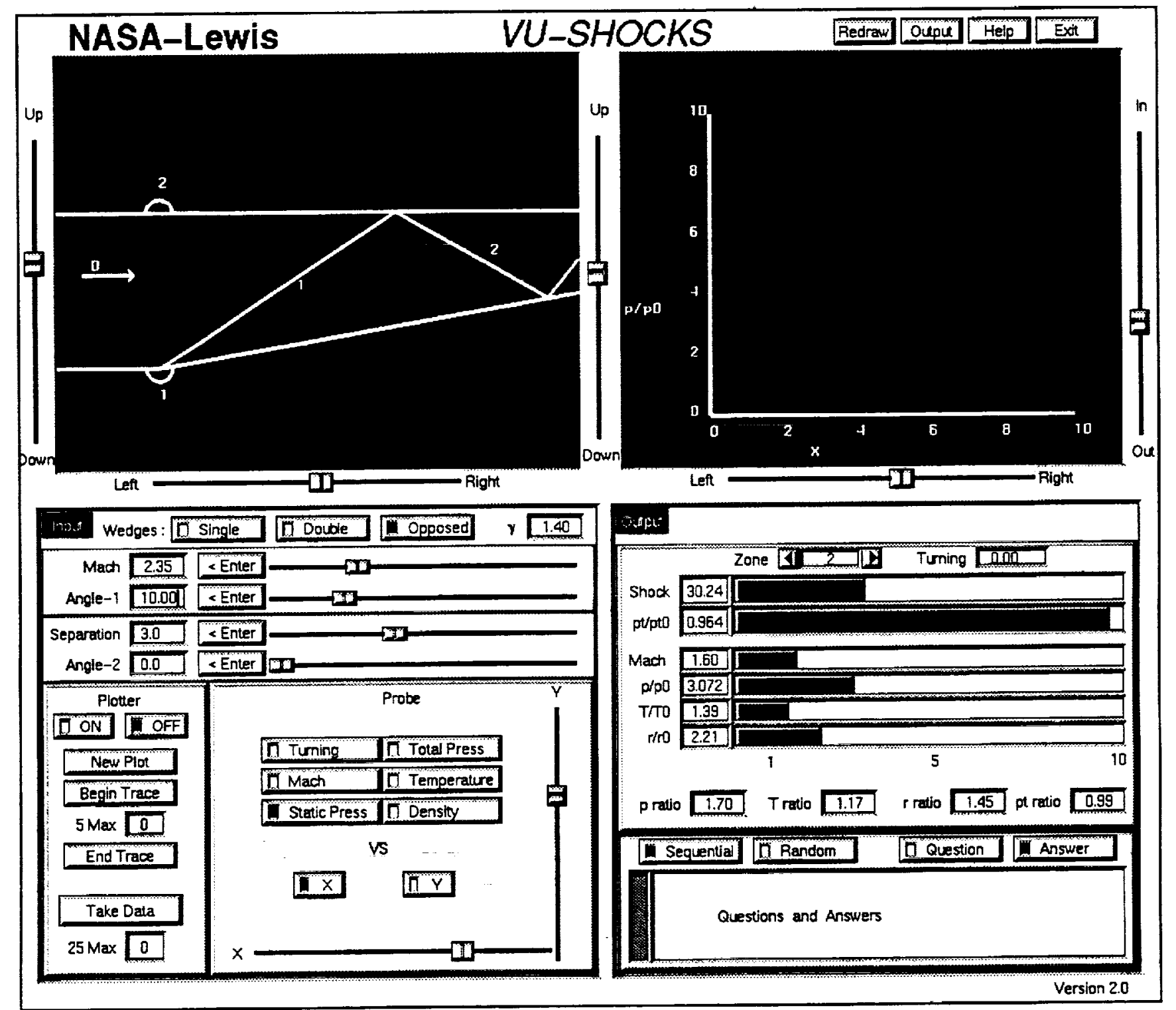

Fig. 5 Reflecting shock solution. 


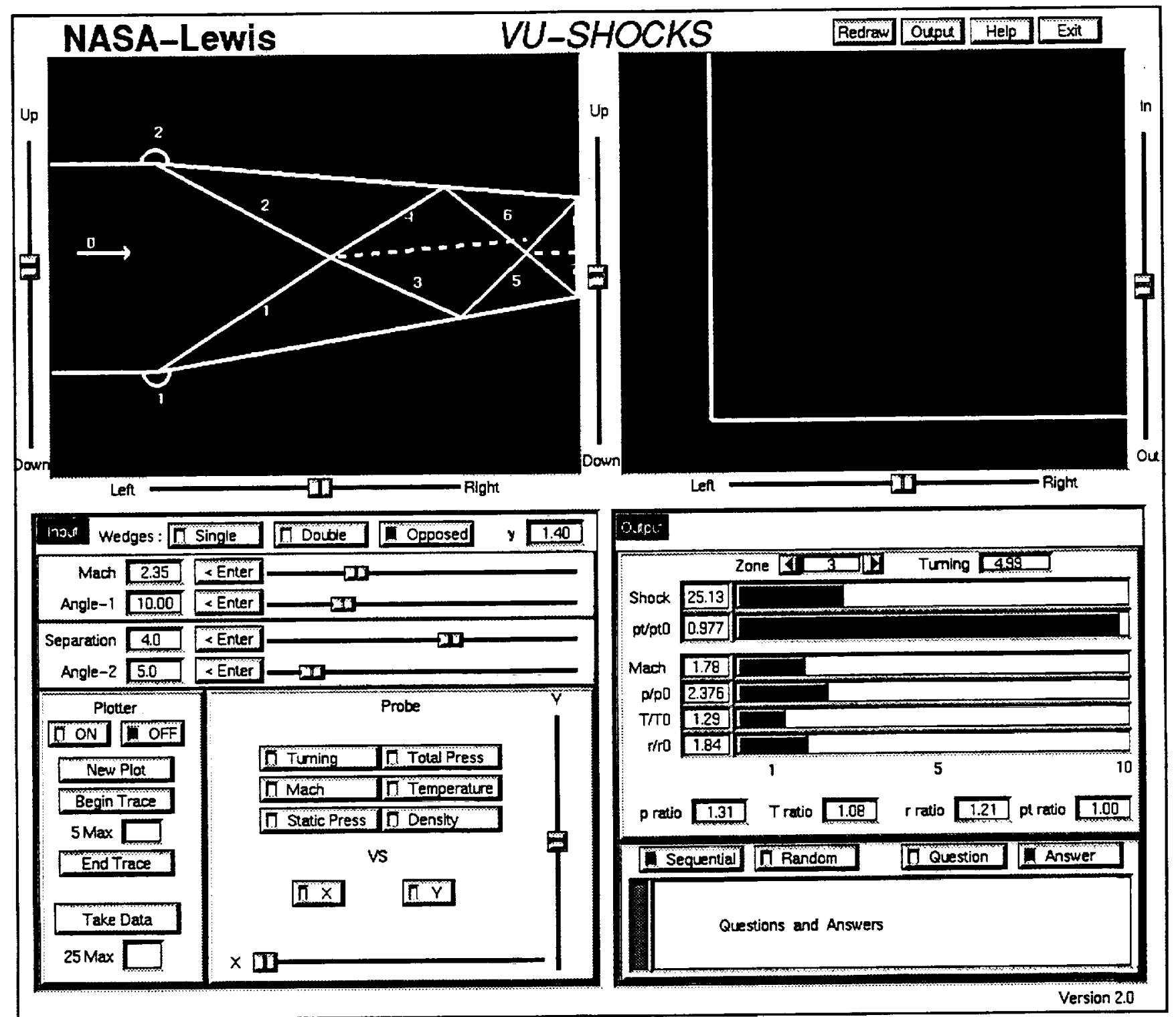

Fig. 6 Flow past opposing wedges. 


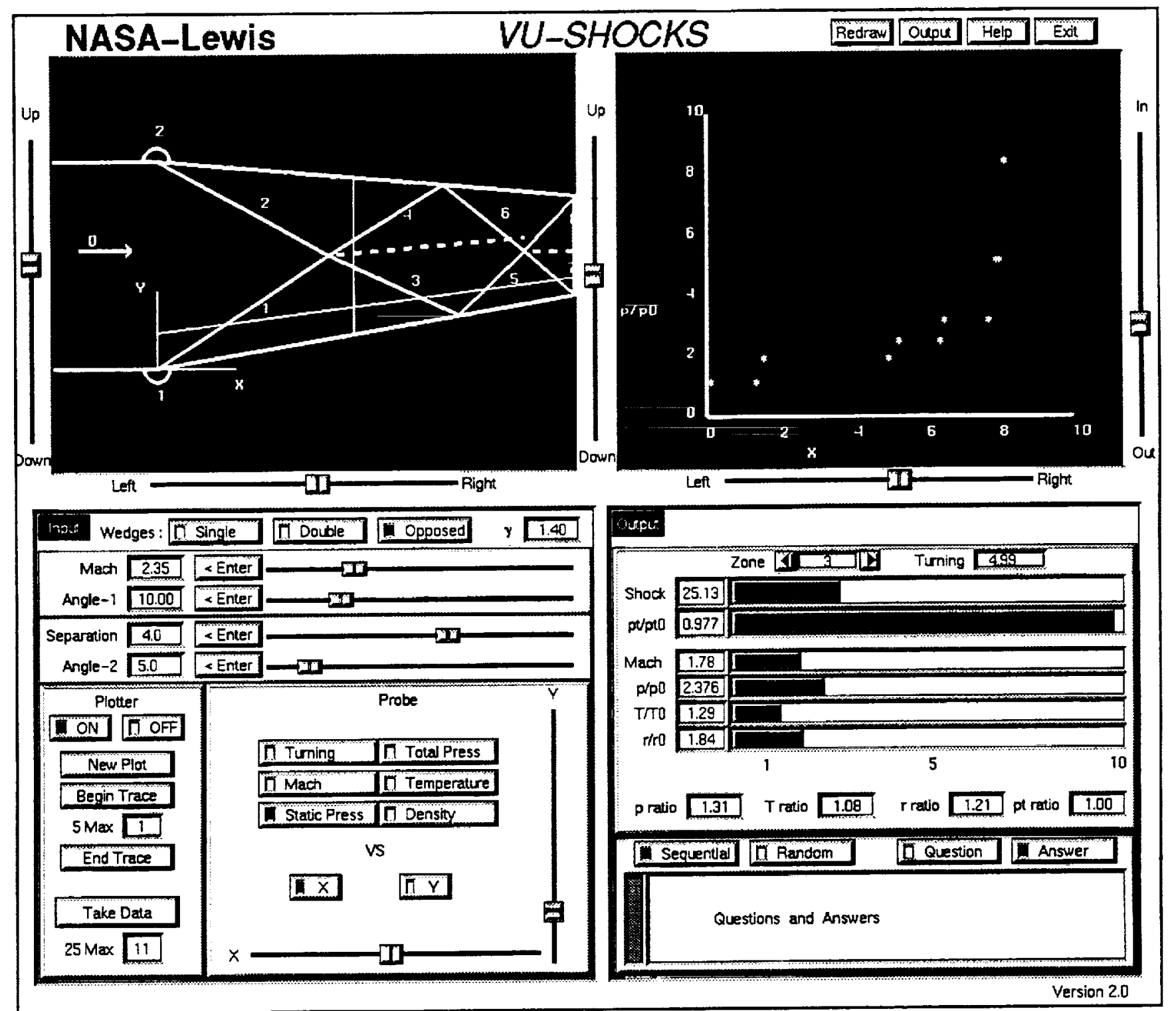

Fig. 7 Plotter initiated. 


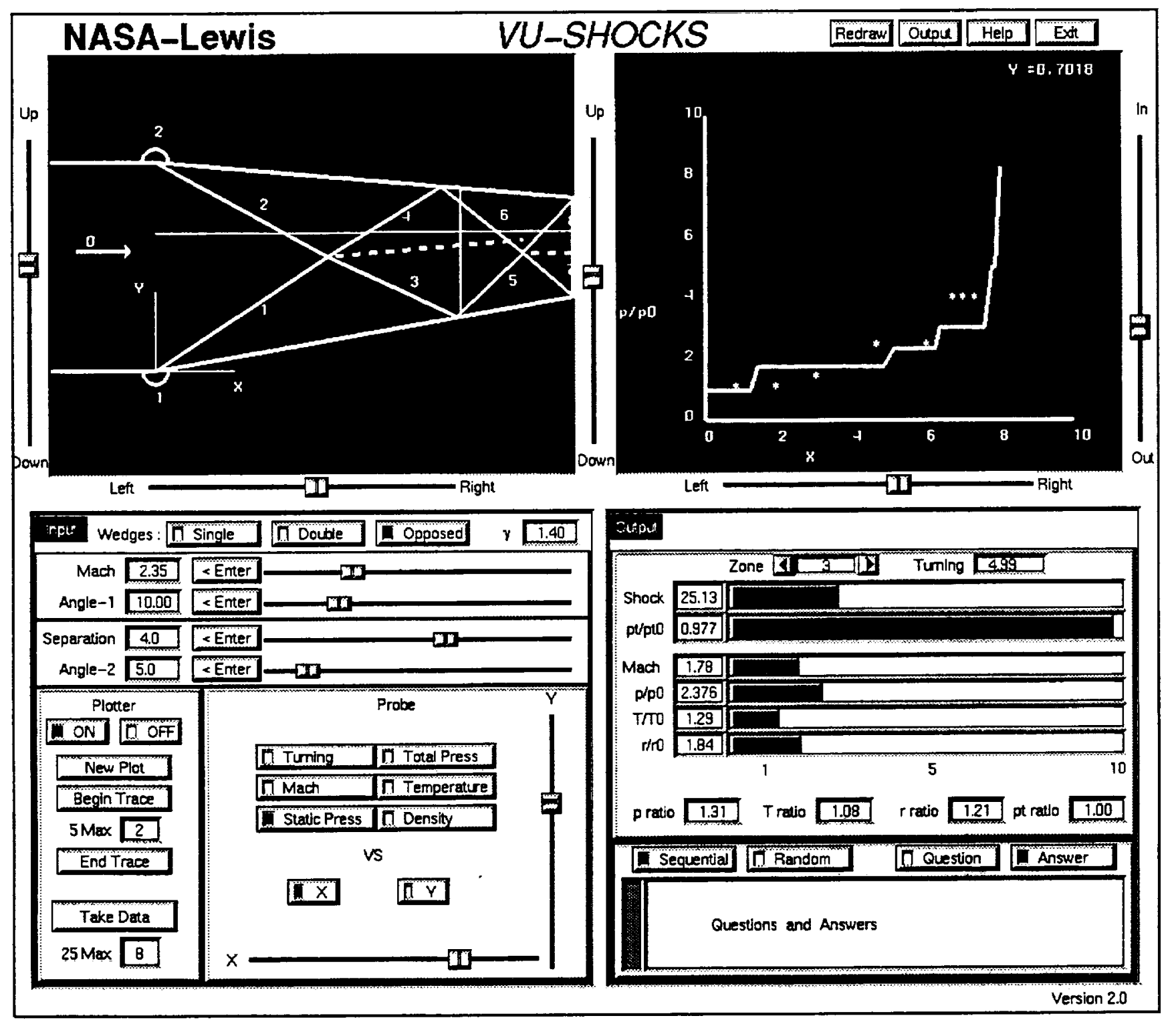

Fig. 8 Plot completed. 
Public reporting burden for this collection of information is estimated to average 1 hour per response, including the time for reviewing instructions, searching existing data sources, gathering and maintaining the data needed, and completing and reviewing the collection of intormation. Send comments regarding this burden estimate of any other aspect of this collection of infomation, including suggestions for reducing this burden, to Washington Headquaners Services, Directorate for Intormation Operations and Reports, 1215 Jefle

Davis Highway. Suht 1204, Arlington, VA 22202-4302, and to the Ottice of Management and Budget, Paperwork Reduction Project (0704-0188), Washing
\begin{tabular}{|l|l|l|} 
1. AGENCY USE ONLY (Leave blanK) & 2. REPORT DATE & 3. REPORT TYPE AND DATES COVERED
\end{tabular}

\section{December 1994}

4. TITLE AND SUBTITLE

A Workstation Based Simulator for Teaching Compressible Aerodynamics

\section{AUTHOR(S)}

5. FUNDING NUMBERS

WU-505-62-52

Thomas J. Benson

\section{PERFORMING ORGANIZATION NAME(S) AND ADDRESS(ES)}

National Aeronautics and Space Administration

Lewis Research Center

Cleveland, Ohio 44135-3191
8. PERFORMING ORGANIZATION REPORT NUMBER

E-9275

10. SPONSORINGIMONITOAING AGENCY REPORT NUMBER

NASA TM-106799

AIAA-95-0070

National Aeronautics and Space Administration

Washington, D.C. 20546-0001$$
\text { ATAA-95-0070 }
$$

\section{SUPPLEMENTARY NOTES}

Prepared for the 33rd Aerospace Sciences Meeting sponsored by the American Institute of Aeronautics and Astronautics, Reno, Nevada, January 9-12, 1995. Responsible person, Thomas J. Benson, organization code 2670, (216) 433-5920.

\begin{tabular}{l|l|l}
\hline 12a. DISTRIBUTIONAVAILABILTV STATEMENT & 12b. DISTRIBUTION CODE \\
Unclassified - Unlimited & \\
Subject Category 61 & \\
This publication is available from the NASA Center for Aerospace Information, (301) 621-0390. & \\
\hline
\end{tabular}

13. ABSTRACT (Maximum 200 words)

A workstation-based interactive flow simulator has been developed to aid in the teaching of undergraduate compressible aerodynamics. By solving the equations found in NACA 1135, the simulator models three basic fluids problems encountered in supersonic flow: flow past a compression comer, flow past two wedges in series, and flow past two opposed wedges. The student can vary the geometry or flow conditions through a graphical user interface and the new conditions are calculated immediately. Various graphical formats present the results of the flow calculations to the student. The simulator includes interactive questions and answers to aid in both the use of the tool and to develop an understanding of some of the complexities of compressible aerodynamics. A series of help screens make the simulator easy to learn and use.

\begin{tabular}{l} 
14. SUBJECT TERMS \\
Educational; Software \\
\hline $\begin{array}{c}\text { 17. SECUATY CLASSIFICATION } \\
\text { OF REPORT } \\
\text { Unclassified }\end{array}$ \\
$\begin{array}{c}\text { 18. SECURITY CLASSIFICATION } \\
\text { OF THIS PAGE } \\
\text { Unclassified }\end{array}$ \\
\hline
\end{tabular}

\begin{tabular}{|c|c|}
\hline & $\begin{array}{l}\text { 15. NUMBER OF PAGES } \\
06\end{array}$ \\
\hline & $\begin{array}{r}\text { 16. PRICE CODE } \\
\mathrm{AO2}\end{array}$ \\
\hline $\begin{array}{l}\text { 19. SECURITY CLASSIFICATION } \\
\text { OF ABSTRACT } \\
\text { Unclassified }\end{array}$ & 20. LIMITATION OF ABSTRACT \\
\hline
\end{tabular}




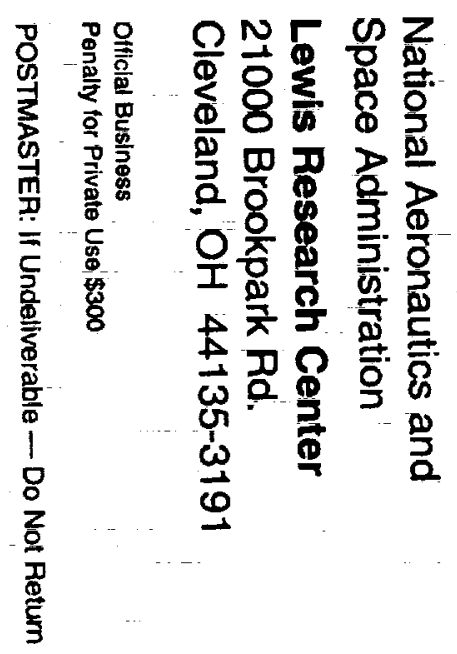


